\title{
Phase Transformation of Rice Husk Ash in the Synthesis of ZSM-5 without Organic Template
}

\author{
Didik Prasetyoko $^{1,2,}$, , Neneng Ayunanda ${ }^{1}$, Hamzah Fansuri $^{1}$, Djoko Hartanto ${ }^{1}$ \& \\ Zainab Ramli ${ }^{3}$ \\ ${ }^{1}$ Material Chemistry and Energy Laboratory, Department of Chemistry, \\ Faculty of Mathematics and Sciences, Institut Teknologi Sepuluh Nopember, \\ Kampus ITS Sukolilo, Surabaya, Jawa Timur 60111, Indonesia \\ ${ }^{2}$ Energy Laboratory, Center of Energy Study, Institut Teknologi Sepuluh Nopember, \\ Kampus ITS Sukolilo, Surabaya, Jawa Timur 60111, Indonesia \\ ${ }^{3}$ Department of Chemistry, Faculty of Science, Universiti Teknologi Malaysia, \\ Johor Bahru 81310, Malaysia \\ E-mail: didikp@chem.its.ac.id
}

\begin{abstract}
Phase transformation of rice husk ash in the synthesis of ZSM-5 without organic template at various crystallization times has been studied. Zeolite has been synthesized using the hydrothermal method at $175{ }^{\circ} \mathrm{C}$ with molar ratio $10 \mathrm{Na}_{2} \mathrm{O}: 100 \mathrm{SiO}_{2}: 2 \mathrm{Al}_{2} \mathrm{O}_{3}: 1800 \mathrm{H}_{2} \mathrm{O}$ with addition of silicalite- 1 as seed. Solids were characterized using X-ray diffraction (XRD), infrared (IR) spectroscopy and scanning electron microscopy (SEM) techniques. Analysis of the results of XRD and IR spectroscopy indicated that ZSM-5 crystalstarted to form at $12 \mathrm{~h}$ of crystallization time, reaching high crystallinity after $24 \mathrm{~h}$. With a crystallization time of more than $48 \mathrm{~h}$, the ZSM-5 crystals had completely transformed into more stable quartz phase. Results indicated that phase transformation has occurred, in which an amorphous phase of rice husk ash has been transformed to ZSM-5 crystal phase during the early crystallization stage and continued to transform to disordered $\alpha$-cristobalite phase and lastly quartz phases. SEM showed that the morphology of the ZSM-5 crystal was of an irregular hexagonal shape with particle size distribution around 3-7 $\mu \mathrm{m}$.
\end{abstract}

Keywords: crystallization time; phase transformation; rice husk ash; template-free; ZSM-5.

\section{$1 \quad$ Introduction}

Rice is the main agricultural product in Indonesia and other agrarian countries. The milling of rice yield about $72 \%$ of rice, $5-8 \%$ of bran, and $20-22 \%$ of husk [1]. Although rice husk is an abundant by-product of rice milling, it is only used as material for burning bricks or just thrown away. Rice husk contains $20-22 \%$ ash and 78-80\% volatile organic material (lignin, cellulose, sugar) [2]. Krishnarao, et al. [3] reported various ranges of rice husk ash (RHA), from 13 to $29 \%$, depending on the rice variety, climate and geographical location. The

Received December $2^{\text {nd }}, 2011$, Revised March $1^{\text {st }}, 2012,2^{\text {nd }}$ Revision May $3^{\text {rd }}, 2012$, Accepted for publication October $18^{\text {th }}, 2012$.

Copyright (C) 2012 Published by LPPM ITB, ISSN: 1978-3043, DOI: 10.5614/itbj.sci.2012.44.3.5 
most common valuable component of rice husk ash is silica $\left(\mathrm{SiO}_{2}\right)$, about 90 $98 \%$, with a small amount of alkali and metal impurities.

Silica is widely utilized in the fields of electronics, mechanics, arts, as well as the manufacture of chemical compounds, including the manufacture of zeolite. One zeolite, ZSM-5 (Zeolite Socony Mobile-5), is widely used as heterogeneous catalyst in the petroleum industry and for fine chemicals production. It is usually synthesized using commercial silica in the form of silica gel, silica sol and fumed amorphous silica. However, waste materials with a high silica content such as rice husk ash (RHA) or coal fly ash (CFA), are potential alternative silica sources for zeolite synthesis.

Previous studies have shown that rice husk ash in amorphous and crystalline forms can be used as a source of silica for the synthesis of zeolite, either with or without templates [4-6]. Ramli and Bahruji [7] reported the synthesis of ZSM-5 using rice husk ash as silica source with tetrapropylammonium (TPA) as an added organic template. Kim, et al. [8] and Cheng, et al. [9] reported the synthesis of nanosize ZSM-5 in the absence of an organic template with a fast crystallization time. The use of an organic template such as TPA in the synthesis of ZSM-5 means higher production costs, liquid waste contamination by the organic template, and possible air pollution from the product of thermal decomposition of the organic template. Therefore, it is preferable to synthesize the zeolite without organic templates [10-14].

Budianto [15] has reported the synthesis of ZSM-5 from rice husk ash without organic template, by adding $1 \%$ of seed to help the crystallization process. The use of a seed crystal to help crystallization has also been reported by Weitkamp and Puppe [16] in the synthesis of the MFI type of zeolites. According to Vempati, et al. [17], the seed accelerated the crystallization process and improved the structure of the resulting ZSM-5.

Although ZSM-5 was successfully synthesized from RHA without organic template, as reported by Budianto [15], no study has been done on the phase transformation of the solid sample during crystallization for a longer period of crystallization time. This work reports a study of the phase transformation of an amorphous gel mixture containing silica of rice husk ash during the synthesis of ZSM-5 without addition of an organic template.

\section{Experiment}

\subsection{Materials Preparation}

The rice husk (obtained from Surabaya, East Java) was first washed with distilled water and then dried at $100{ }^{\circ} \mathrm{C}$ for $24 \mathrm{~h}$ before burning at $600{ }^{\circ} \mathrm{C}$ for $4 \mathrm{~h}$ 
in air. The resulted rice husk ash was characterized using XRD technique. Synthesis of ZSM-5 without organic template was done by the addition of a seed crystal. The reaction mixture contained $\mathrm{NaOH}$ (99wt\%; Merck), sodium aluminate (technical grade, $\mathrm{Al}$ as $\mathrm{Al}_{2} \mathrm{O}_{3} 50-56 \mathrm{wt} \%$, $\mathrm{Na}$ as $\mathrm{Na}_{2} \mathrm{O}$ 40-45wt\%; Sigma Aldrich), rice husk ash $\left(\mathrm{SiO}_{2}, 93 \mathrm{wt} \%\right)$ and calcined silicalite-1 as seed crystal. The reaction mixture was prepared with molar composition: $10 \mathrm{Na}_{2} \mathrm{O}$ : $100 \mathrm{SiO}_{2}: 2 \mathrm{Al}_{2} \mathrm{O}_{3}: 1800 \mathrm{H}_{2} \mathrm{O}$. Initial silica and alumina mixtures were prepared separately in two teflon beakers, A and B. Beaker A contained a mixture of $\mathrm{NaOH}$, water and rice husk ash, while beaker B contained sodium aluminates and water. Both beakers were stirred for two $\mathrm{h}$. The reaction mixture in beaker $\mathrm{B}$ was added to beaker A, and stirred for $6 \mathrm{~h}$. The resulting gel mixture was aged for $12 \mathrm{~h}$ at room temperature before being transferred to a stainless steel autoclave. Then calcined silicalite- 1 seed $(1 \mathrm{wt} \%)$, which was previously prepared in our laboratory [18] was added to the mixture. Subsequently, the mixture was heated at $175^{\circ} \mathrm{C}$ with a variation of the crystallization times i.e. 6 , $12,24,48$, and $96 \mathrm{~h}$. The autoclave was then cooled to room temperature to stop the crystallization process. The solid was filtered and washed with distilled water until the washing water became neutral. Finally, the solid was dried at $110{ }^{\circ} \mathrm{C}$ for $12 \mathrm{~h}$. and characterized with XRD, FT-IR spectroscopy and SEM techniques.

\subsection{Characterization}

The phase of the samples was determined by X-ray diffraction (Philips PN-1830 X-ray Diffractometer) using Ni-filtered CuK $\alpha$ radiation $(\lambda=1.5406 \AA)$ at $40 \mathrm{kV}$ and $40 \mathrm{~mA}$. The pattern was scanned in the $2 \theta$ ranges $5-50^{\circ}$ at a step size of $0.010^{\circ}$ and a step time of $1 \mathrm{~s}$. The infrared spectra of the samples were recorded on a Shimadzu FTIR, with scans $20 \mathrm{~s}$ using the $\mathrm{KBr}$ pellet method, in the wavenumber range of 1400-400 $\mathrm{cm}^{-1}$. Scanning Electron Microscopy was monitored on a JEOL 6303 LA to determine the surface morphology of the samples.

\section{$3 \quad$ Results and Discussion}

The rice husk sample was burned at $600^{\circ} \mathrm{C}$ and the as-synthesized solids at different crystallization times were characterized by X-ray diffraction technique in the range of $2 \theta=5-50^{\circ}$, as shown in Figure 1. The XRD pattern of the rice husk ash sample (Figure 1(a)) shows a hump in the region $2 \theta=15-30^{\circ}$. This indicates that the ash contains amorphous material $[19,20]$.

Figures 1(a-e) present the XRD patterns of the synthesized samples at various crystallization times. The XRD pattern of the sample crystallized for $6 \mathrm{~h}$, (Figure 1(b)) also shows a hump at $2 \theta=15-30^{\circ}$, indicating that the sample still 
contained amorphous material. This suggests that the sample had not yet been converted to zeolite phase. We have reported earlier that the transformation of rice husk ash involves the dissolution of silica ash in the early stages of crystallization [6].

The XRD pattern of the sample crystallized for $12 \mathrm{~h}$ (Figure 1(c)) shows a very small peak at $2 \theta=22.97^{\circ}$ indicating an early formation of ZSM-5 crystal [21]. However, the sample still contained amorphous material as the hump still appeared in the diffractogram of the sample. Meanwhile, the sample crystallized for $24 \mathrm{~h}$ (Figure 1(d)) shows full crystal phase with diffraction peaks at $2 \theta 7.88$, $22.97,23.23,23.63,23.85$ and $24.33^{\circ}$. This XRD pattern matches well with the XRD of reference of ZSM-5 [21], indicating that ZSM-5 type zeolite has been formed. The XRD pattern of the sample shows a high intensity of the signal with the absence of a hump, suggesting that only ZSM-5 crystal is present in the sample, with good crystallinity.

Figure 1(e-g) show the XRD patterns of the samples that have been crystallized for 48,72 and $96 \mathrm{~h}$ respectively. The XRD of the sample crystallized for $48 \mathrm{~h}$ (Figure 1(e)), shows additional peak at $2 \theta=21.97^{\circ}$. This peak is assigned to the disordered $\alpha$-cristobalite phase [21]. The intensity of the highest peak characteristic for ZSM-5 at $2 \theta=22.97^{\circ}$ of this sample is lower than that of the peak of the sample crystallized for $24 \mathrm{~h}$. This observation suggests that the crystallinity of ZSM-5 has decreased, while some of the ZSM-5 crystal phase has undergone dissolution. The silicate rich solution and the high alkali media of the reaction mixture that was used in this experiment havefacilitated the growth of disordered $\alpha$-cristobalite, a type of silica crystal phase.

With a prolonged crystallization time, several phase transformations were observed. The XRD pattern of the sample crystallized for $72 \mathrm{~h}$ is shown in Figure 1(f). All peak patterns for ZSM-5 phase have completely disappeared in this sample, with only two peaks at $2 \theta=20.8$ and $26.59^{\circ}$. The peaks match well with the quartz phase [21], which suggests that the ZSM-5 phase has completely transformed to the more stable quartz phase [21]. However, in the sample crystallized for $96 \mathrm{~h}$, a reappearing of the ZSM-5 phase is visible in the XRD in Figure $1(\mathrm{~g})$. The reappearing of a small peak at $2 \theta=7.9$ and 22.97 indicates that some quartz crystal has re-dissolved into the reaction mixture, while the available aluminate species in the reaction mixture have facilitated the reformation of ZSM-5 crystals. After $72 \mathrm{~h}$ of crystallization, the peak intensity of $\mathrm{I}_{100}$ at $2 \theta=26.59^{\circ}$ of quartz has decreased from $7111 \mathrm{cps}$ in the sample crystallized for $72 \mathrm{~h}$ to $3493 \mathrm{cps}$ in the sample crystallized for $96 \mathrm{~h}$, which indicates the decrease crystallinity of the quartz phase (also shown in Figure 2). 


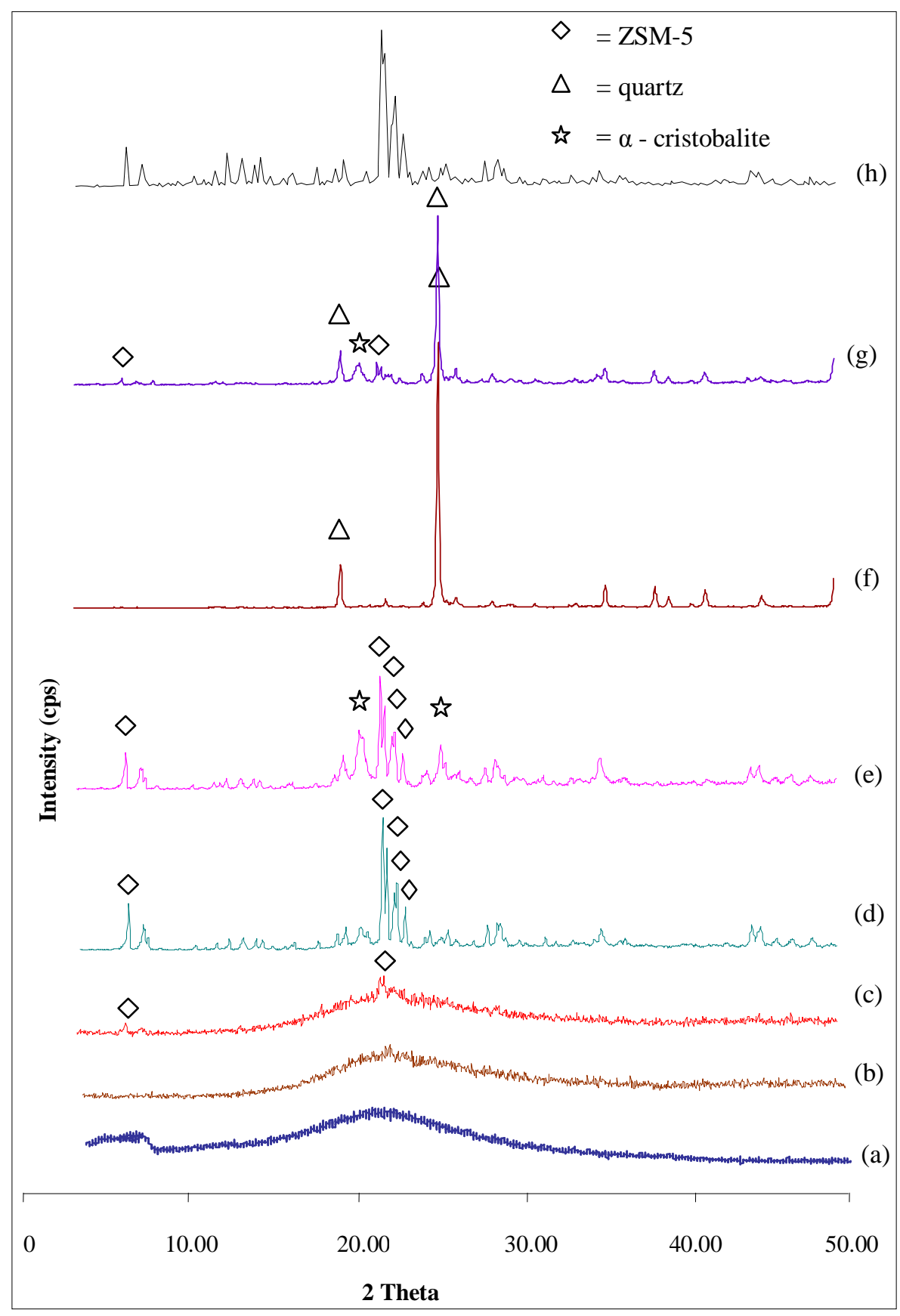

Figure 1 XRD patterns of (a) rice husk ash, and samples at various crystallization times: (b) $6 \mathrm{~h}$, (c) $12 \mathrm{~h}$, (d) $24 \mathrm{~h}$, (e) $48 \mathrm{~h}$, (f) $72 \mathrm{~h}$, (g) $96 \mathrm{~h}$, (h) ZSM-5 from TEOS-TPABr. 
All the findings indicate that phase transformations have occurred in the solid samples in which crystallization proceeded, from the amorphous phase of the aluminosilicate gel mixture to the ZSM-5 phase, continued to the disordered $\alpha$-cristobalite phase, and to the more stable quartz phase. The transformation of the amorphous aluminosilicates gel to the crystalline phases is presented in Figure 2, showing a plot between the crystallization times versus the total intensity of each phase. On the basis of the XRD results, we can conclude that pure ZSM-5 can be obtained in $24 \mathrm{~h}$ crystallization time with the gel ratio used in this study and the help of seed crystals. In the reaction mixture used in this experiment, which was highly alkaline, and with the absence of an organic template as structure-directing agent, the formed ZSM-5 crystal is metastable and prone to re-dissolve and facilitate the formation of a more stable silica crystal such as quartz, with a prolonged crystallization time. Different findings of silica transformation were also reported by Barrer [22] in at different system solution at high temperature, where the transformation of amorphous silica followed the sequence: amorphous $\rightarrow \alpha$-cristobalite $\rightarrow$ keatite $\rightarrow$ quartz.

Assuming the ZSM-5 phase in the sample crystallized for $24 \mathrm{~h}$ to $100 \%$, the relative crystallinity of the ZSM-5 phase formed in samples at 12, 24, 48, 72 and $96 \mathrm{~h}$ crystallization time have been calculated, the results are shown in Table 1 . The difference in intensity observed in the XRD patterns is due to the difference in crystallinity of the ZSM-5 samples, which can also indicates the amount of ZSM-5 contained in the solid sample.

Table 1 XRD peak intensity and crystallinity of the samples with various crystallization times.

\begin{tabular}{cccccc}
\hline \multirow{2}{*}{$\mathbf{\theta}$} & \multicolumn{5}{c}{ Intensity, cps } \\
\cline { 2 - 6 } & $\mathbf{1 2} \mathbf{~ h}$ & $\mathbf{2 4} \mathbf{~ h}$ & $\mathbf{4 8} \mathbf{~ h}$ & $\mathbf{7 2} \mathbf{~ h}$ & $\mathbf{9 6} \mathbf{~ h}$ \\
\hline $7.88-8.75$ & 44.92 & 483.42 & 319.50 & - & 112.07 \\
$22.51-22.97$ & 89.53 & 1479.68 & 932.52 & 38.26 & 382.41 \\
$22.99-23.23$ & - & 1131.99 & 702.71 & - & - \\
$23.48-23.63$ & - & 557.98 & 406.83 & - & - \\
$23.83-23.85$ & - & 751.09 & 488.44 & - & - \\
$24.31-24.46$ & - & 476.28 & 290.29 & - & - \\
\hline $\begin{array}{c}\text { ZSM-5 } \\
\text { Crystallinity } \\
(\%)\end{array}$ & 2.75 & 100 & 64.54 & 0.79 & 10.13 \\
\hline
\end{tabular}




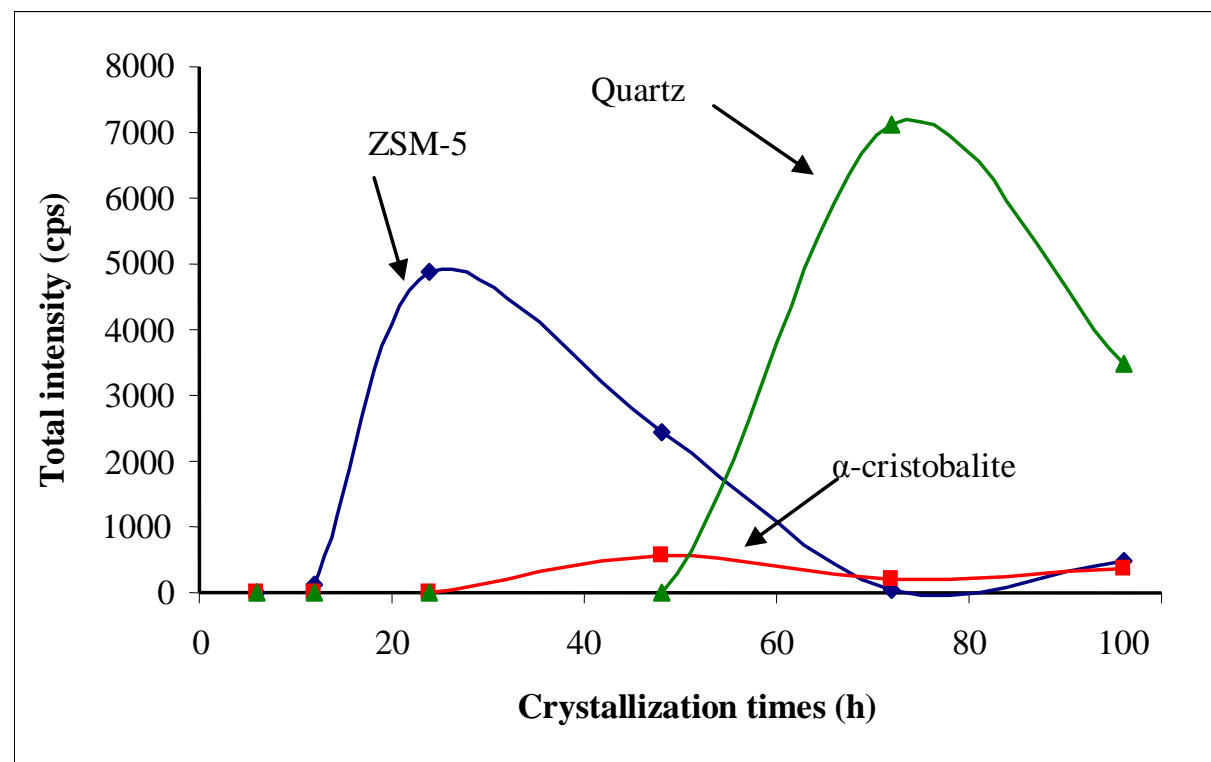

Figure 2 Transformation of amorphous silica to ZSM-5, disordered $\alpha$ cristobalite and quartz phase.

The infrared spectra of the rice husk ash and the samples at various crystallization times were recorded at wavenumber in the range of 1400-400 $\mathrm{cm}^{-1}$ as shown in Figure 3, the wavenumbers of each peak are tabulated in Table 2. The infrared spectrum of the rice husk ash in Figure 3(a) shows the characteristics of the asymmetric stretching of the tetrahedral $\mathrm{SiO}_{4}$ peaks at wavenumber $1099 \mathrm{~cm}^{-1}$, the symmetry stretching of $\mathrm{SiO}_{4}$ at $c a .799 \mathrm{~cm}^{-1}$ and the bending of Si-O at $467 \mathrm{~cm}^{-1}[23,24]$. The third peak of the rice husk ash spectrum, at $467 \mathrm{~cm}^{-1}$, indicates that the rice husk ash is in the form of amorphous phase [25]. Figure 3(b) and (c) represent the infrared spectra of the solid samples crystallized for 6 and $12 \mathrm{~h}$ respectively. The spectra of these samples appear almost the same as the spectrum of the rice husk ash. This indicates that the ZSM-5 crystal has not yet been formed in these samples, which agrees well with the XRD finding.

The infrared spectrum of the sample crystallized for $24 \mathrm{~h}$ (Figure 3(d)) shows a vibrational peaks pattern in the ZSM-5 framework. Peaks at around 1102, 796 and $456 \mathrm{~cm}^{-1}$ are characteristic for the asymmetric stretching of the tetrahedral $\mathrm{TO}_{4}(\mathrm{~T}=\mathrm{Si}, \mathrm{Al})$ and the $\mathrm{T}-\mathrm{O}$ bending, respectively. The appearance of a shoulder peak at $1218 \mathrm{~cm}^{-1}$, which is assigned to the asymmetric stretching of the external framework and at $542 \mathrm{~cm}^{-1}$, which is assigned to five-membered ring vibration, are characteristic for an MFI zeolite framework, ZSM-5 belongs to this group of zeolite $[25,26]$. These two vibrational peaks are sensitive to the 
framework changes while the appearance of five-membered ring vibration at $542 \mathrm{~cm}^{-1}$ confirms the ZSM-5 structure because the ZSM-5 framework structure is made of such 5-membered rings of $\mathrm{TO}_{4}$ tetrahedral building units. The IR spectrum of the sample supports the data from the XRD. The spectrum is also in accordance with the result reported by Flanigen, et al. [23], and also with the spectrum of ZSM-5 synthesized from commercial silica (tetraethylorthosilicate, TEOS) in the presence of an organic template (tetrapropyl ammonium bromide, TPABr) as is shown in Figure 3(h).

The sample crystallized for $48 \mathrm{~h}$ had a similar infrared pattern (Figure 3(e)) to the infrared spectrum of the sample crystallized for $24 \mathrm{~h}$, which indicates that the sample still maintained the ZSM-5 structure. However the peaks that are sensitive to the structure change in ZSM-5 (ca. 1218 and $542 \mathrm{~cm}^{-1}$ ) started to decrease in intensity and disappeared in samples crystallized for longer than 48 $\mathrm{h}$ (Figure 3(f and $\mathrm{g})$ ). This observation agrees well with the XRD results in which there samples consist of quartz as the dominant phase. By looking at the asymmetric stretching peak for the samples crystallized for 24 and $48 \mathrm{~h}$, both of which consist of ZSM-5 phase, the sample crystallized for $24 \mathrm{~h}$ is suggested to be more siliceous than the sample crystallized for $48 \mathrm{~h}$ because the peak appears at a higher frequency, i.e. at $1102 \mathrm{~cm}^{-1}$ rather than $1096 \mathrm{~cm}^{-1}$. This means that the sample crystallized for $24 \mathrm{~h}$ contains more silica due to the substitution of aluminium atoms with silicon atoms in the framework. According to Armaroli, et al. [27], the ZSM-5 with high aluminum content shows an asymmetric stretching band at around $1090 \mathrm{~cm}^{-1}$.

Table 2 Stretching and bending vibration of the samples.

\begin{tabular}{cccccccc}
\hline \multirow{2}{*}{ Samples } & \multicolumn{3}{c}{ TO $\mathbf{4}$ stretching } & \multicolumn{2}{c}{ T-O bending } \\
\cline { 2 - 5 } & \multicolumn{2}{c}{ Asymmetric } & Symmetric & & & \multirow{2}{*}{ T-O } \\
\hline Rice husk ash & - & 1099 & 799 & - & 467 & - \\
$6 \mathrm{~h}$ & - & 1089 & 796 & - & 468 & - \\
$12 \mathrm{~h}$ & - & 1088 & 798 & - & 468 & - \\
$24 \mathrm{~h}$ & $1218(\mathrm{sh})$ & 1102 & 796 & 542 & 478 & 456 \\
$48 \mathrm{~h}$ & $1218(\mathrm{sh})$ & 1096 & 793 & 546 & - & 457 \\
$72 \mathrm{~h}$ & - & 1086 & 800 & 581 & 473 & - \\
$96 \mathrm{~h}$ & - & 1098 & 799 & - & 473 & - \\
ZSM-5 from & 1228 & 1109 & 800 & 550 & 457 & - \\
TEOS-TPABr & & & & & & &
\end{tabular}




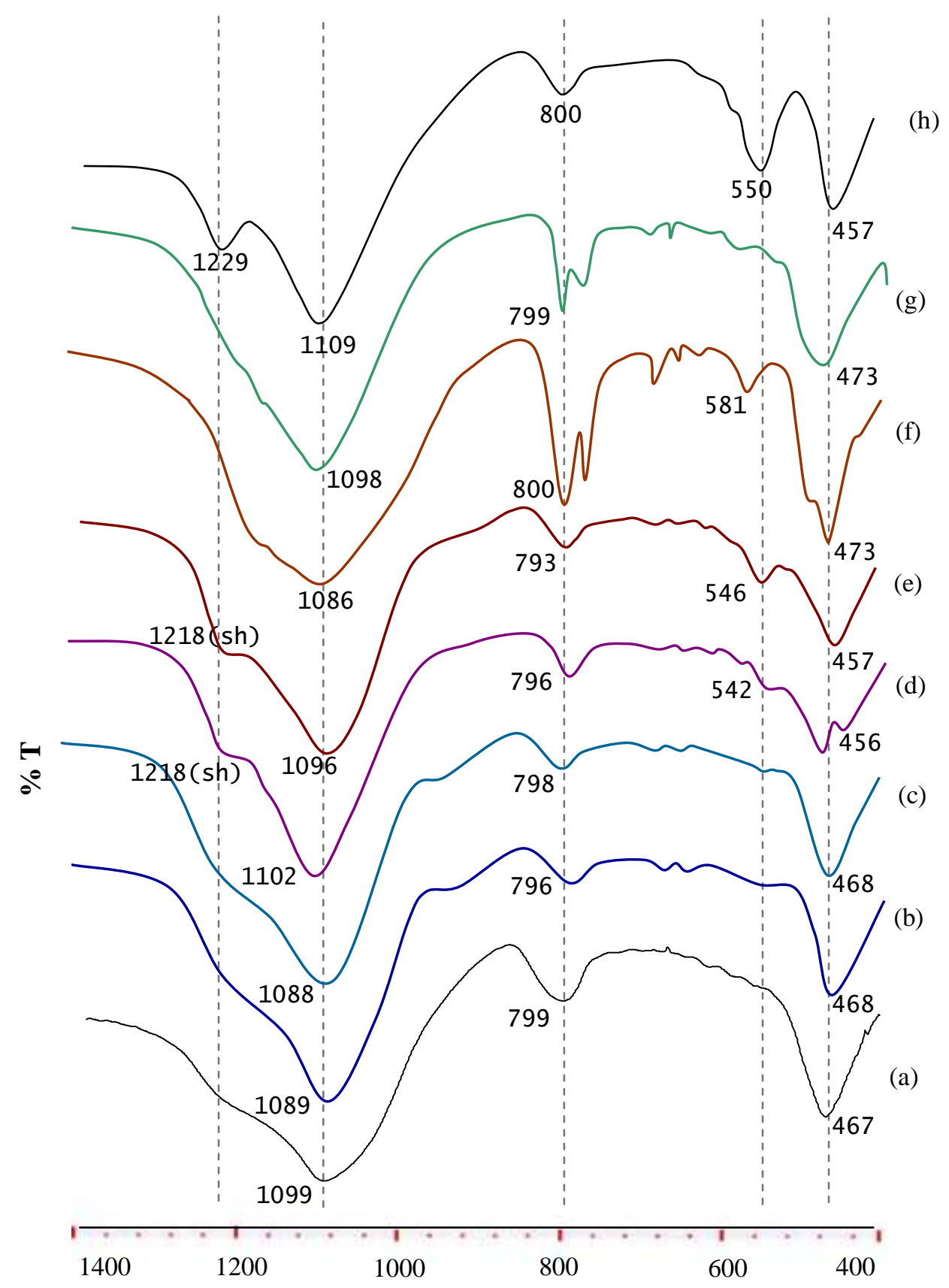

Figure 3 Infrared spectra of the samples: (a) rice husk ash (b) 6 h (c) 12 h (d) $24 \mathrm{~h} \mathrm{(e)} 48 \mathrm{~h}$ (f) $72 \mathrm{~h}$, (g) $96 \mathrm{~h}$ and (h) ZSM-5 from TEOS-TPABr. 
The SEM of the rice husk ash sample crystallized for $24 \mathrm{~h}$, and the ZSM-5 synthesized using TEOS and organic template TPABr are shown in Figure 4. The morphology of the rice husk ash appears as aggregates in various size around 50-100 $\mu \mathrm{m}$ with no definite structure, suggesting the presence of amorphous material. Some flaky layers with a needle-like structure can be observed at the aggregate particle (Figure 4(a)). The flaky morphology of the sample of amorphous silica aggregates, as seen in the SEM images, shows a reactive surface that can easily make bonds [19]. The morphology of the sample crystallized for $24 \mathrm{~h}$ is shown in Figure 4(b). In general, this sample displays an almost uniform, grubby, hexagonal like crystal, spread evenly with a varying particle size, ranging between $1-5 \mu \mathrm{m}$. For comparison, the morphology of the ZSM-5 synthesized using TEOS as silicon source and TPABr is shown in Figure 4(c). It can be observed that the morphology of the crystals consists of layers of agglomerated hexagonal crystal-shapes resulting in a much larger crystal, with an average size of $20 \mu \mathrm{m}$ as compared to $5 \mu \mathrm{m}$ for the ZSM-5 synthesized from rice husk ash.

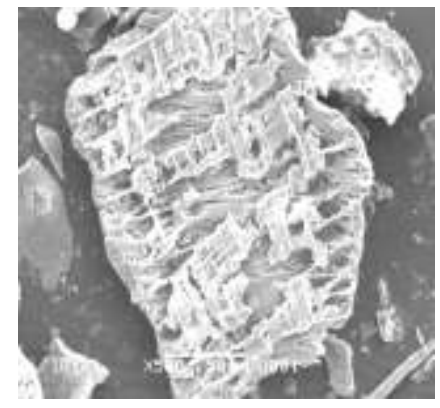

(a)

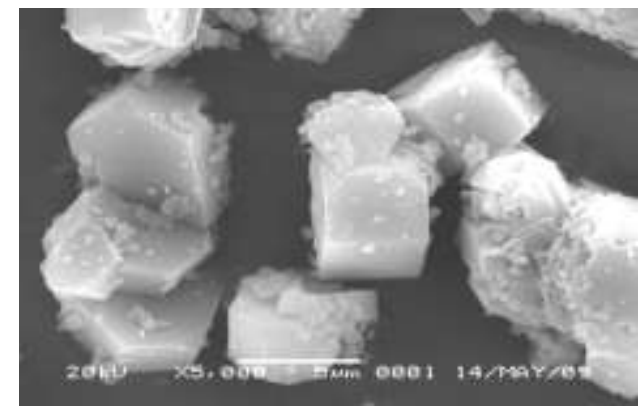

(b)

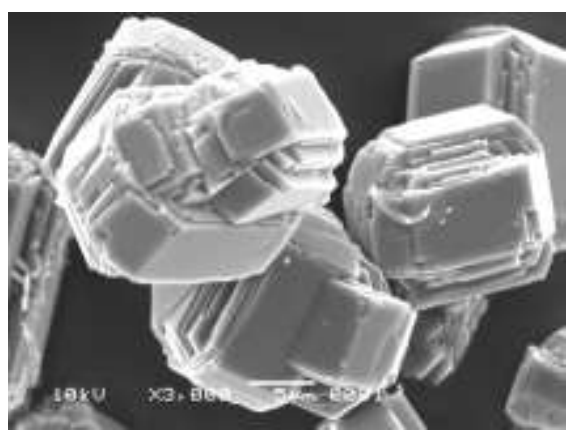

(c)

Figure 4 SEM of (a) rice husk ash, (b) sample with $24 \mathrm{~h}$ crystallization time (c) ZSM-5 from TEOS-TPABr. 


\section{Conclusion}

Pure ZSM-5 with a particle size between 3-7 $\mu \mathrm{m}$ can be synthesized from rice husk ash as silica source within $24 \mathrm{~h}$ of crystallization time without an organic template and with the addition of silicalite- 1 as seed crystal. The ZSM-5 phase started to form after $12 \mathrm{~h}$ of hydrothermal crystallization and reached maximum crystallinity and purity at $24 \mathrm{~h}$ of crystallization. The ZSM-5 crystal formed is metastable since with a longer crystallization time the ZSM-5 crystal was transformed into the more stable quartz phase.

\section{Acknowledgments}

The authors gratefully acknowledge the financial support from Institut Teknologi Sepuluh Nopember (ITS), Surabaya.

\section{References}

[1] Prasad, C.S., Maiti, K.N. \& Venugopal, R., Effect of Rice Husk Ash in Whiteware Compositions, Ceramic International, 27, pp. 629-635, 2001.

[2] Yalçin, N., \& Sevins, V., Studies on Silica Obtained from Rice Husk, Ceramic International, 27, pp. 219-224, 2001.

[3] Krishnarao, R.V., Subrahmanyam, J. \& Kumar, T.J., Studies on The Formation of Black in Rice Husk Silica Ash, Journal of European Ceramic Society, 21, pp. 99-104, 2001.

[4] Bajpai, P.K., Rao, M.S. \& Gokhale, K.V.G.K., Synthesis of Mordenite Ttype Zeolite Using Silica from Rice Husk Ash, Industrial \& Engineering Chemistry Product Research and Development, 20, pp. 721-726, 1981.

[5] Wang, H.P., Lin, K.S., Huan, Y.J., Li, M.C. \& Tsaur, L.K., Synthesis of Zeolite ZSM-48 from Rice Husk Ash, Journal of Hazardous Materials, 58, pp. 147-152. 1998.

[6] Prasetyoko, D., Ramli, Z., Endud, S., Hamdan, H., \& Sulikowski, B., Conversion of Rice Husk Ash to Zeolite Beta, Waste Management 26, pp. 1173-1179, 2006.

[7] Ramli Z. \& Bahruji H., Synthesis of ZSM-5 Type Zeolite Using Crystalline Silica of Rice Husk Ash, Malaysian Journal of Chemistry, 5 (1), pp. 48-55, 2003.

[8] Kim S.D., Noh S.H., Seong K.H. \& Kim W.J., Compositional and Kinetic Study on the Rapid Crystallization of ZSM-5 in The Absence of Organic Template, Microporous and Mesoporous Materials, 72, pp. 185192, 2004.

[9] Cheng, Y., Wang L.j., Li, J.S., Yang, Y.C. \& Sun X.Y., Preparation and Characterization of Nanosized ZSM-5 Zeolite in The Absence of Organic Template, Materials Letters, 59, pp. 3427-3430, 2005. 
[10] Shiralkar V.P. \& Clearfield, A., Synthesis of the Molecular-sieve ZSM-5 without the Aid of Templates, Zeolites, 9, pp. 363-370, 1989.

[11] Otake, M., MFI Zeolite Crystallization under Controlled Dosage of TPA Template, Zeolites, 14(1), pp. 42-52, 1994.

[12] Grose, R.W. \& Flaningen, E.M., Novel Zeolite Compositions and Processes for Preparing and Using Same, US Patent 4, pp. 257,885, 1981.

[13] Ren, N., Bronić, J., Subotić, B., Lv, X.C., Yang, Z.J. \& Tang, Y., Controllable and SDA-free Synthesis of Sub-micrometer Sized Zeolite ZSM-5. Part 1: Influence of Alkalinity on the Structural, Particulate and Chemical Properties of the Products, Microporous and Mesoporous Materials, 139, pp. 197-206, 2011.

[14] Huang, X. \& Wang, Z., Synthesis of Zeolite ZSM-5 Small Particle Aggregates by a Two-Step Method in the Absence of an Organic Template, Chinese Journal of Catalysis, 32, pp. 1702-1711, 2011.

[15] Budianto, S.A., Sintesis Zeolit ZSM-5 dari Abu Sekam Padi Tanpa Templat Organik, Thesis Master, Chemistry-ITS, Surabaya, 2007.

[16] Weitkamp, J. \& Puppe, L., Catalysis and Zeolites Fundamentals Application, Germany, 1999.

[17] Vempati R.K., Borade, R., Hegde, R.S. \& Komarneni S., Template Free ZSM-5 From Siliceous Rice Hull Ash With Varying C Contents, Microporous and Mesoporous Materials, pp. 134-140, 2006.

[18] Prasetyoko, D., Ramli, Z., Endud, S. \& Nur, H., Characterization of Bifunctional Oxidative and Acidic Catalysts $\mathrm{Nb}_{2} \mathrm{O}_{5} / \mathrm{TS}-1$ for Synthesis of Diols, Materials Chemistry and Physics, 93, pp. 443-449, 2005.

[19] Hamdan, H, Mohd Muhid, M.N., Endud, S., Listiorini, E. \& Ramli Z., Si MAS NMR, XRD and FESEM Studies of Rice Husk Silica for The Synthesis of Zeolites, Journal of Non Crystalline Solids, 211, pp. 126131, 1997.

[20] Della, V.P., Kühn, I. \& Hotza, D., Rice Husk Ash an Alternate Source for Active Silica Production, Materials Letters, 57(4), pp. 818-821, 2002.

[21] Treacy, M.M.J. \& Higgins, J.B., Collection of Simulated XRD Powder Patterns for Zeolites, Structure Commision of the International Zeolite Associacion, Amsterdam, 4th Edition, 2001.

[22] Barrer, R.M., Hydrothermal Chemistry of Zeolites, Academic Press, London. 1982.

[23] Flanigen E.M., Khatami, H. \& Szymanski, Infrared Structural Studies of Zeolite Frameworks, in Adv. Chemistry Series, 101, American Chemical Society, Washington, D.C., pp. 201-228, 1971.

[24] Mozgawa, W., Handke, M., Jastrze,bski, W., Vibrational Spectra of Aluminosilicate Structural Clusters, Journal of Molecular Structure, 704, pp. 247-257, 2004. 
[25] Shukla, D.B. \& Pandya, V.P., Estimation of Crystalline Phase in ZSM-5 Zeolites by Infrared Spectroscopy, Journal of Chemical Technology and Biotechnology, 44, pp. 147-154, 1989.

[26] Kirschhock, C.E.A., Ravishankar, R., Verspeurt, F., Grobet, P.J., Jacobs, P.A. \& Martens, J.A., Identification of Precursor Species in the Formation of MFI Zeolite in the TPAOH-TEOS- $\mathrm{H}_{2} \mathrm{O}$ System, Journal of Physical Chemistry B, 103, pp. 4965-4971, 1999.

[27] Armaroli, T., Simon, L.J., Digne, M., Montanari, T., Bevilacqua, M., Valtchev, V., Patarin, J. \& Busca, G., Effects of Crystal Size and Si/Al Ratio on the Surface Properties of H-ZSM-5 Zeolites, Applied Catalysis A: General, 306, pp. 78-84, 2006. 